\title{
Muslim Communities in the New Europe
}

Edited by Gerd Nonneman, Tim Niblock, and Bogdan Szajkowski. Reading, England: Garnet Publishing Limited, 1996, 346 pp.

Although Muslim Communities in the New Europe is long and complex, it is not obscure, and each of its sixteen chapters can be read as a separate entity. The 
contributors are seventeen academics from universities in various countries of Eastern and Western Europe, as well as the three editors who are based at three English universities. A short preface is followed by the first chapter, which is also the first part of the book, appropriately titled "Themes and Puzzles." The remaining chapters examine selected countries individually in Eastern and Western Europe in parts II and III, respectively. Each chapter has helpful and clear endnotes, and a useful index is also included. Tables analyzing the Muslim populations in East European countries are given in chapter 2 and those of Belgium and The Netherlands in chapter 10.

In the Preface, the book is described as the "final outcome of a three-year project" to "produce a coherent comparative overview of ... the role and position of these Muslim communities." The material was gathered from two international conferences on the subject and from researchers throughout Europe. Professor Gerd Nonneman modestly states: "This volume cannot claim to be comprehensive, but ... it is hoped that it may contribute to a better understanding of the trends and dynamics involved, and provide the basis for further work."

Chapter 1 outlines the events leading up to the present general situation in the new Europe. The continent is divided into (1) Eastern Europe, where, after the collapse of Communism at the end of the 1980s, strong nationalist and religious feelings erupted; and (2) Western Europe, which, during a long economic recession, absorbed a sudden large influx of migrants from African and Asian countries suffering serious political and economic upheaval.

In parts II and III the contributors seek to answer a wide range of important questions concerning the relationship between Muslims and non-Muslims in Europe generally and between Muslims and non-Muslim governments in particular. How significant is the influence of history, the current economy, the origins of the Muslims and the level of their adherence to Islam, local and central government policies, local customs, international relations, public opinion, and so on? How does the reaction of the younger generation of Muslims to their situation compare with that of their parents? Throughout the studies of the selected countries, the fear of the perceived loss of security and identity seems to be at the root of action and reaction by both Muslims and non-Muslims. How far can the minority and majority societies adapt to each other without either side losing its identity and security? Possible solutions to the problems of integrating Muslims into non-Muslim societies are suggested by some of the contributors.

Chapter 2 examines the links between religion and ethnicity in Eastern Europe, where Islam has been "an indigenous presence for centuries." Although Islam is independent of race, color, and language, "around the fringes of the Islamic world" it is the basis of the identity of certain groups within nationalities, such as the Bosnian Muslims and Bulgarian Pomaks.

The contributors then tackle one of the puzzles, that of how to define ethnicity. They describe the current theories, which put varying emphasis on the objective elements of kinship, physical appearance, culture, and language, and the subjective elements, namely, the "feeling of community" and the "representations which the group has of itself" (p. 28).

Another puzzle is how to estimate the number of Muslims in East European countries. The contributors point out that these communities "are among the least researched of the world's Muslim groupings," and "there is not even agreement on ... who can be included" (p. 30). The few statistics that are available show such enormous discrepancies (which are well illustrated in the tables) as to confuse the issue even further. It is hoped that as the former Communist coun- 
tries of Eastern Europe develop settled political and economic structures, more reliable information will be forthcoming.

The third part of chapter 2 looks at the "very small" Muslim minority-mostly Tatars - in Poland. Over the centuries the Tatars supported the Poles in their struggle against Russian and German domination, their patriotism being "admired by Poles and non-Poles alike." The contributors conclude that the "interaction between Islam and ethnicity has provided the crucial dynamic which had maintained communities" (p. 38). The example of the Muslims in Poland is a "useful model" of the positive relationship between a minority and the national community, where the minority's contribution to the nation is appreciated and the government allows those people to retain their identity.

Chapters 3 and 4 analyze Macedonia, a country with a large minority of ethnic Albanians - a mostly Muslim, tightly knit society-officially estimated to comprise 23 percent of the population. In chapter 3 the contributor discusses the political situation of the Albanians, who have demanded "partner-nation status" in a government that is mainly Macedonian Orthodox Christian. The government, politically and economically shaky since independence in 1991, has been opposed to this, lest it result in secession and civil war. The contributor suggests that the government concentrate on the material advancement of the Albanians, thereby reducing the emphasis on status and increasing the credibility of moderate leaders within their community. He presents clearly the fears and aspirations of both sides, not forgetting the responsibilities of each to the other if a stable society is to be created.

The three contributors to chapter 4 examine the Muslims in Macedonia as a religious minority rather than as an ethnic group, although most of them are Albanian. A survey carried out in 1991 showed a disturbingly marked increase in prejudice compared with the traditional "high degree of religious tolerance." This had largely resulted from the myth of "endangered Orthodoxy" and "Muslim conspiracy" created by "political manipulation." The contributors emphasize the perceived "isolation" of the Muslims in education, employment, and social life, where their lifestyle and practices conflict with state policy and the customs of the majority. As a solution, it is recommended to establish a "civic society," in which religion and politics would be separated and all citizens would have equal rights under the law. However, one wonders how much the contributors known about Islam: twice on page 80 they refer to "clerics," who do not exist in Islam, for it has no priesthood. Perhaps they mean scholars or teachers.

In chapter 5 the contributor gives a concise and very readable history of Bosnia from its beginnings in the tenth century to the "human tragedy" of the 1990s. Following the Ottoman occupation in the fifteenth century, many Bosnians converted to Islam. Through the centuries and during Austrian rule from 1978 to the First World War, administration of the country was balanced between the three main religious groups: Muslim, Orthodox, and Catholic, a system "strongly reiterated by Bosnian's Muslim leaders in the 1990s" (p. 103). However, although two pages are devoted to Bosnia in the Second World War, there is no mention of its participation the First World War, apart from the assassination of Archduke Ferdinand.

Postwar Serbian domination and fear of the Islamization of Bosnia culminated in the rejection of the 1992 referendum of supporting "an independent Bosnia consisting of citizens with equal rights" (p. 111) and provoked outright civil war, which the Muslim leadership had hoped to avoid. The contributor describes 
the country's sad situation neatly and sympathetically: "Since 1992, the Bosnian Muslim community - the oldest such community in Europe- . . . has been fighting for its very existence.... The case of the Bosnian Muslims illustrates the need for basic humanity and basic rules of co-existence in post-Communist Europe" (p. 114).

Chapter 6 begins with a detailed analysis of the population of Bulgaria, of which 16 percent are estimated to be Muslims. Most of the Muslims are ethnic Turks, the rest comprising ethnic Bulgarians (or Pomaks) and Roma (Gypsies). The contributors describe in graphic detail the problems suffered by the Muslim minorities: socially and economically disadvantaged, sometimes to the point where, for example, ethnic Turks - usually the better educated - are obliged to migrate to Turkey. The Roma, particularly the Muslims, are at the bottom of the social ladder, and "traditionally ... the group most neglected by the Bulgarian state" (p. 128). "'Religion' per se" is less "a belief system than ... an element of ethnic/national identification-especially in the face of economic, social and political pressures. Bulgaria's future will depend in part on the depth of the national leadership's understanding of internal ethnic and religious issues" (p. 134).

In chapter 7 the contributor examines Albania, a mostly Muslim country where Islam survived many years of enforced atheism under Communist rule, and where there has been "an upsurge of religious feelings" since the coming of democracy in 1991. The increasing influence of Islam, reinforced by economic aid from Muslim countries, is shown in education, dress, and Albania's membership in the Organization of Islamic Countries (OIC). As a counterbalance, the government also seeks closer links with Western Europe and the Vatican, and so "the situation does ... remain in a degree of flux, and so does the balancing act in foreign relations" (p. 151).

Chapter 8 discusses the position of the (mostly Turkish) Muslims in Greece, where "even if the extent of actual discrimination ... can be vigorously debated," it seems "that there is a significant sense of discrimination among sections of the minority" (p. 163). Despite the protection of the Lausanne Convention of 1923, they suffer the same problems as Muslim minorities elsewhere: Disadvantaged in education, religious freedom, employment, citizenship, and the economy, many are forced to migrate to Turkey. However, the contributor points out that the Greek Orthodox minority in Turkey has also suffered "hostility and legal harassment by the Turkish authorities" (p. 161). This has led to allegations and counterallegations by the Greek and Turkish governments, including the wider issues of Cyprus and the Aegean. There seems to be no solution to these "problematic questions."

Part II (Western Europe) begins with chapter 9 on the Muslims in Britain. As in other West European countries after the Second World War, guest workers from Africa, Asia, and the Caribbean were encouraged by the British government to come to Britain and fulfill the "need for cheap labor for undesirable jobs" (p. 169). The influx of dependents and refugees in later years created communities whose requirements made a marked impact on education, health, and welfare services. The early Muslim immigrants "managed to gain ... significant concessions" despite "their own unfamiliarity with British local government structures and British ignorance of Islamic values" (p. 175). However, it has been the second generation, educated as British citizens yet among the first to be affected by mass unemployment, which has played a particularly active part in politics. 
Muslims do face religious discrimination and hostility, especially during an economic recession or when the British government is at loggerheads with the governments of certain Muslim countries. The contributor does not support the current government policy of multiculturalism, which "exacerbates separatist and isolationist views among Muslims and non-Muslims alike" (p. 183). Instead, he suggests "a pattern of localized institutions, effective and truly representative umbrella organizations . . . enabling . . . greater Muslim freedom, equality and participation" (p. 184).

Chapter 10 looks at an unusual but useful aspect of Islam by discussing the effect of its transplantation to Belgium and The Netherlands from the immigrants' countries of origin. As in other parts of Western Europe, Muslim immigrants come from a wide range of countries and cultures, and most of the mosques established in Belgium and The Netherlands "are characterized very strongly by the socio-national connections of their members" (p. 204). The contributors analyze the different levels of the immigrants' adherence to their faith against the influence of Western social, economic, and political structures. They also examine in some detail the efforts of an equally wide range of Islamic organizations seeking to "re-Islamize" the Muslim immigrants.

Islam is now recognized in Belgium and The Netherlands and "irrevocably forms part of society" (p. 215). Owing to the "umma's diversity" and its lack of a coordinated and committed representation, however, there has been little discussion with the governments about the future of the Muslim communities. The contributors rightly emphasize the urgency of solving this problem to avoid serious repercussions and to institutionalize "Islam as a new 'pillar' of these societies" (p. 216).

Chapter 11 presents a very different picture in France, where the official policy is the imposition upon Muslim immigrants of assimilation into a secular society. The contributor asks the question, "Who constitutes a 'Muslim'?" (p. 220); Muslims comprise not only guest workers (now settled) from all kinds of backgrounds, but also their children brought up in France and educated in secular state schools. It is pointed out that "part of the weakness of Islam in France is due to its internal divisions and the lack of a single, institutionally recognized authority through which to negotiate its place vis-à-vis state and civil society" (p. 219), a problem facing Muslim minorities in most West European countries.

"Difference" is contrary to French political and cultural identity, and consequently Muslims of every generation are marginalized socially economically. The type and degree of hostility toward Muslims in France are examined at some length: from the government's aim of containing Islam by controlling the appointment of imams, to the xenophobia of "traditional French Catholic 'identity"” (p. 223). The final section of the chapter is devoted to "France, French Islam and the Algerian question," the last being a particularly sensitive topic in a country where "the colonial past is still very much present" (p. 222). The contributor cannot see any resolution of the many problems without more cohesion on the part of the Muslims and more tolerance and understanding and less stereotyping on the part of the government and the rest of the population.

Chapter 12 analyzes the situation of Muslims in Germany, especially the Turkish guest workers, who form the majority of Muslim immigrants. As the Muslim community has increased with the addition of dependents and secondgeneration immigrants, so have the problems it faces in education (religious education is a detailed example), employment, and its relations with the state and German population. Islam has "become increasingly the subject of fears and 
resentment in the host society" (p. 241). These problems are fully described and illustrated with useful examples.

The contributors also examine the changes in the practice of Islam by the immigrants in a Westernized secular setting (officially Christian) and the attitudes of the second-generation Muslims to their faith. Close links with Turkey are maintained through a wide range of Islamic organizations with varying degrees of religious, social, and political influence. Unlike France, for example, there has been a "clearer momentum towards the creation of a central body that could represent the interests of Muslims in the majority society" (p. 259), which has resulted in two umbrella organizations. It seems that "the integration of Islam . . . must be conducted in the framework of a society-wide concensus on the free democratic principles underpinning the German state" (p. 243).

The contributor of chapter 13 examines the Muslim communities in Sweden from the sociological point of view, and the chapter is largely based on his fieldwork among them. Sweden is described as an isolated country on the northern edge of Europe, neither a colonial power nor a "very attractive target for emigration" (p. 272).

The influx of Muslim immigrants and refugees from the 1980 s onwards created a conflict with the "formula" on which the country had been developed since the sixteenth century: "One nation, One people, One religion" (p. 272). Although Sweden's immigration policy officially advocates multiculturalism, in practice ethnic, cultural, and religious groups are seen as a threat to national stability. The government expects immigrants to be assimilated into the Swedish way of life in public and to keep differences strictly to the private domain in the hope that they will be eradicated altogether over time. Swedish society considers itself to be materially superior to the rest of the world and is shocked to discover that many Muslims do not agree, wishing to preserve their Islamic lifestyle based on different values.

The contributor presents the arguments on both sides in careful detail, pointing out that repression and marginalization by Swedish society only lead to increased "religious and ethnic mobilization" by the Muslims for the equality to which they are legally entitled. He advises the Swedes to take a good look at their society and "learn to handle and solve [these conflicts] in a democratic and constructive way" (p. 287).

Chapter 14 studies the Muslims in Denmark, particularly from the aspect of employment (or lack of), and the marked change in the attitude of the Danes toward immigrants in the 1980s and 1990s. Like Sweden, Denmark had no previous experience of Islam before the importing of foreign labor from Muslim countries in the 1960 s to cope with the economic boom. The temporary guest workers settled and were joined by their families and later by large numbers of political refugees. The increase in immigration coincided with an economic recession, resulting in widespread unemployment mostly affecting the immigrants. From being "welcomed and looked upon as a necessity in order to provide continued economic growth" (p. 293), immigrants now represented "an economic burden on, and a threat to, the existing social welfare system" (p. 296).

"The main targets of criticism are Islam and Muslims" (p. 294), such feelings being stirred up by the media and politicians of the extreme left and right. The contributor asks the pertinent question: "Why is it that Islam and Muslims are subject to attack, and not refugees from Vietnam, with their Buddhist religion, or the Tamil refugees and their Hinduism?" (p. 299). The answer is possibly his- 
torical, dating back to the Middle Ages and the Crusades. Since then, the "hostile image of Islam has been revived" (p. 299), and Islam is made the "explanation for all problems related to immigrants and refugees" (p. 300).

At the time of publication of this book, the Muslims' reaction to the situation had not been researched. The contributor poses a number of questions that need to be tackled and refers to a committee for ethnic equality set up in 1993, "which may provide ... religious and ethnic minorities ... with a platform from which they may raise a voice against discrimination" (p. 300).

Chapter 15 is a careful, detailed analysis of the Muslim community in Spain, a country unique in Western Europe in having been an important part of the Islamic empire and its civilization for eight centuries. After four centuries of "cultural and religious isolation,... . historical reconciliation" came about with the recognition of Islam in 1989. Both immigrant and nonimmigrant Muslim groups are covered, including the recent native converts, which are hardly mentioned elsewhere in the book, apart from Italy. The large proportion of Spanish converts may be explained by "greater religious freedom . . . together with the social disappointment of new generations" leading to "a search for different ways of life" and "historical roots" (pp. 304 and 305). The early Muslim immigrants were a few students and professionals from the Middle East. They were later joined by political refugees, also from the Middle East, and then by large numbers of economic migrants from North Africa and Sub-Saharan Africa.

Although the (better-educated) Muslims from the Middle East have integrated fairly successfully into Spanish society, the (less-educated) economic migrants are rejected not only by other Muslims but also by working-class Spaniards, who see them as competition for fewer jobs and descendants of the historically hated "Moors." The xenophobia seems to be targeted toward immigrants in general rather than Muslims in particular. However, there is a popular feeling that Islam is a "symbol of violence, fanaticism and backwardness" (p. 311). The contributor concludes that to improve integration and avoid serious problems in the future, Spain must "reproduce some of the original religious and cultural aspects of [the Muslims'] lives" (p. 312) and facilitate the development of the Muslim community.

Chapter 16 concentrates on Italy, beginning with "the return of Islam." There was "Islamic domination" of Sicily for two centuries; "Islamic heritage is visible" still on the Italian coast. Otherwise, "in 20th-century Italian culture, Islam remains an unknown quantity" (p. 315), apart from the enemy "Saracen" pirates of folklore. (There is no mention of the annexation of Libya in 1912.)

Until the early 1970 s Italy was a country of emigration rather than immigration. The early Muslim incomers were an elite group of students from the Middle East. In the 1980 s and 1990 s their numbers were rapidly increased by a large influx of political refugees and economic migrants from various parts of Africa and Asia, as well as Bosnia and Albania.

The influence of internal and external religious and cultural organizations is muted owing to the wide diversity of nationalities. Native converts play an important role in the media and as spokespeople for Islam in Italian society, although the contributor is dubious about the effect of the "radical and militant" image of Islam which they portray. However, so far, "Italy presents the spectrum of a relatively acceptable level of social integration of the Muslim communities" (p. 321). The most visible group comprises the illegal immigrants, who survive as street sellers and smugglers. 
Relations between Muslims and the government are also "relatively good," although better at the local level than at the national one. To obtain equality of status with other religious minorities, it is necessary to find a body that can truly represent a very varied Muslim community to liaise with and be recognized by the state. However, there is hope. The contributor points out that the Italian (and other European) governments have shown "goodwill towards Islam ... to safeguard economic relations with the oil-rich Middle East" (p. 324).

In addition, the Catholic Church, like Islam, is universal, which implies "respect for the rights of minorities," and "on both sides, there is clear evidence of a desire for mutual understanding" (p. 326).

Thus the book ends on an optimistic note. Nevertheless, apart from Poland and Italy, the representative sample of countries gives a bleak picture of Muslim minorities in Europe, whether the Muslim communities have existed for several centuries or only several decades. Islamophobia seems to develop when the number of Muslims reaches a certain proportion of the national populationwhen Islam becomes "visible" and can no longer be ignored. Governments, unable to appreciate the contribution of Islamic culture and dependent upon the popular vote, are reluctant to give official recognition to a religion that is popularly and historically considered to be foreign and therefore inferior, even dangerous. On the other hand, the Muslim communities, comprising all shades of adherence to Islam - from the privately practicing to the publicly militant-lack sufficient cohesion to produce official representatives to hold serious discussions with host governments. The situation is further complicated by difficulties in relations between the governments of the immigrants' countries of origin and those of the countries of migration.

Certainly there are gaps in the book, although it is true that had they been filled, the text might have been unacceptably long. There is no mention of Islamic banking and finance in Europe, and the position of native converts to Islam is discussed in only two countries. Indeed, these two subjects deserve a book each. Other subjects could be studied separately in greater detail: for example, education, employment, social welfare, the establishment of mosques, and the application of national laws to Muslim communities. The tables add an important dimension to the text, and it would have been helpful - especially to non-European readers - if they had been supplemented with maps or diagrams showing the movement and concentration of Muslim populations.

One of the delightful aspects of this book is that it highlights groups of people - in this case, the Muslim minorities - that are usually bypassed in history books, which tend to concentrate on the activities of the major powers. The text provides a useful and informative foundation not only for students of social history but also for the general reader who is interested in looking at Europe from a different angle. However, it is a book that needs regular updating, say, at least every five years. Since it was published in 1996, life has moved on, for example, Czechoslovakia has been divided into the Czech Republic and Slovakia; the Refat Party has been banned in Turkey; in Albania there has been widespread destitution owing to the collapse of pyramid investments; demands by ethnic Albanians for autonomy in Kosovo has provoked violent suppression by the Serbian government; and in Britain, the Labor government, which came to power after the general election of May 1, 1997, has agreed to provide state funding for two Islamic primary schools in London and Birmingham. 
All in all, the contributors have produced a text that is an intellectual pleasure to read; I eargerly await the publication of its sequel.

Sylvia J. Hunt

Freelance Editor

Wester Ross

Scotland 